\title{
Carbon Policy as a Strategy to Jointly Address Climate Change, Prevent Wildfires and Biodiversity Loss: A Portugal Case Study
}

\author{
Renata Pacheco $^{1}$, João Claro ${ }^{1}$ \\ ${ }^{1}$ INESC TEC and Faculdade de Engenharia, Universidade do Porto, Campus da FEUP, Rua Dr. Roberto Frias, 4200-465 \\ Porto, Portugal \\ renatapacheco@fe.up.pt; jclaro@fe.up.pt
}

\begin{abstract}
Carbon policies, especially emissions taxes, are one of the proposed ways to help tackle climate change, which is one of the century's major challenges. In this context, Portugal has instituted Law N. 82-D/2014, which created the Addition Tax on Carbon Emissions, applied over specific energy and petroleum products. Wildfires, increasing in frequency and intensity, are among the most noticeable impacts of climate change in Portugal. Forests provide several ecosystem services not valued by traditional markets, such as carbon sequestration. Recently, Portugal has created new environmental policies that deal with wildfire prevention and biodiversity conservation through payment for ecosystem services schemes. Both policies have beneficial impacts regarding climate regulation and sequestration. In this scenario, this study aims to develop an order of magnitude analysis of the revenue from the Addition Tax on Carbon Emissions (Law N. 82-D/2014) and contrast it with the investments needed for policies RCM N. 59/2017 and RCM N. 121/2019. These pieces of legislation address issues related to Prescribed Burning and Payment for Ecosystem Services, respectively. Also, we briefly analyse the economic benefits of implementing RCM N. 59/2017. The results indicate that the Addition Tax revenue is much greater than the costs of the other two policies combined, suggesting that these policies can function synergistically, as is advised by the Sustainable Development Goals. In addition, we found evidence that the Portuguese Prescribed Burning policy has positive economic benefits, in addition to its environmental value. This analysis framework might be helpful for other countries, especially in the Mediterranean Basin.
\end{abstract}

Keywords: Wildfire emissions, Forest management, Carbon sequestration, Prescribed burning, Ecosystem services.

\section{Introduction}

Climate change is one of the most significant challenges for humanity in the twenty-first century. One way to reduce greenhouse gas emissions suggested by economic theory is to introduce an emissions tax to internalize its social costs [1]. In Portugal, this type of taxation is introduced by Law N. 82-D/2014, which changed environmental taxation rules in the sectors of energy and emissions, transport, water, waste, land use, forests, and biodiversity, introducing a tax regime for plastic bags and an incentive regime for the disposal of vehicles at the end of the year, as part of a reform of environmental taxation. In its Article 92. ${ }^{\circ}-\mathrm{A}$, the Law creates the Addition Tax on Carbon Emissions applied over specific energy and petroleum products.

The income from this taxation is directed to the Portuguese Environmental Fund (created by Decree-Law No. 42A/2016), which was designed to sponsor sustainable development measures in the country, such as climate action and biodiversity protection. Despite being an intrinsic part of Mediterranean ecosystem dynamics, wildfire is one of the notorious consequences of climate change in Portugal as it increases the occurrence of fire events and their intensity [2], [3], which has been negatively impacting biodiversity in Portugal [4]. Wildfires modify carbon cycles by increasing the atmospheric carbon dioxide $\left(\mathrm{CO}_{2}\right)$ and decreasing the sequestration by terrestrial ecosystems [5], [6].

There is increasing agreement that forestry is an effective way to mitigate climate change among the countries and organizations of the United Nations Climate Conference. Forests can assist in tackling climate change by decreasing greenhouse gas emissions and increasing their absorption, acting as a carbon sink, storing carbon-containing chemicals for indefinite periods. [7]. Climate change adaptation is no different from disaster risk reduction, and actions to tackle it should agree with other sustainable development policies [8]. In this sense, several global policies address the issues that arise from climate change and the surge in forest fires, such as the United Nations Sustainable Development Goals (SDGs), specifically 
Goal 13 - Climate Action and Goal 15 - Life on Land, that address climate regulation and biodiversity issues [9]. Inherent in the SDGs logic is that the goals are dependent on each other [10] and should be tackled in a coordinated fashion.

In agreement with European guidelines, Portugal has established policies to address climate change, wildfires, and biodiversity recovery in the past decades. Portugal signed the Kyoto Protocol in 2002, and the Resolution of the Council of Ministers (RCM) N. 56/2015 approved the Strategic Framework for Climate Policy, the National Program for Climate Change, and the National Strategy for Adaptation to Climate Change. Concerning wildfires, the RCM N. 59/2017 approved the National Prescribed Burning Program, intending to decrease the fire events' extensions. This policy not only helps in avoiding losses in terms of biodiversity, real-state, and potentially lives, but prescribed burning has been shown to reduce overall fire emissions in some Mediterranean countries, like Portugal [2], [5].

In terms of biodiversity, following European guidelines, RCM N. 55/2018 approved the National Strategy for Nature Conservation and Biodiversity 2030, which acknowledges that forest fires endanger biodiversity, stating that Portugal should be in the vanguard in economically valuing ecosystem services. In this sense, RCM N. 121/2019 instated the first Ecosystem Services Payment Program in Rural Spaces in Portugal. This legislation seeks to consider the many vital contributions of forests that are not valued by traditional markets, such as erosion control, carbon sequestration, regulation of the hydrological cycle, conservation biodiversity, reducing susceptibility to fire, and improving landscape quality.

These policies rely on growing scientific evidence and comprehension of climate change and the role forests play in carbon cycles. Landowners need to be compensated appropriately through economic incentives to promote actions to reduce forests' $\mathrm{CO}_{2}$ emissions [11]. It is recognized that by institutionalising incentives for carbon sequestration, for example, a stronger economic rationale can be made for intensifying forest restoration [12]. In this setting, carbon taxation has been proposed as a means to fund forest conservation measures worldwide [13], and that through new governance arrangements, climate change, and forest policies, both for adaptation and mitigation, can be addressed jointly [14].

Portugal has a broad legal apparatus regarding climate change, biodiversity, and forest fire management, and there is literature advocating that a tax on fossil fuels can boost the restoration of ecosystems that help curb climate change [13]. In this context, the objective of this study is to perform an order of magnitude analysis of the revenue from the Addition Tax on Carbon Emissions (Law N. 82-D/2014) and compare it with the investment costs of RCM N. 121/2019 (payment for Ecosystem Services) and of RCM N. 59/2017 (Prescribed Burning Program). The intention is to make a "big picture" analysis of the viability of these policies working synergistically, aiming to address climate change, prevent wildfires and biodiversity loss. Next, we analyse in further detail RCM N. 59/2017 to estimate the economic benefits that can be expected from this policy. As Portugal is considered a characteristic representative of the Mediterranean region for forest-management interventions [15], this analysis can be a valuable approach for other countries in the region and perhaps in other mediterranean-climate regions of the world.

\section{Materials and Methods}

This study is divided into two main parts. First, we perform an order of magnitude analysis of the revenues from the Addition Tax and compare it with the investments needed for the Prescribed Burning Program and Payment for Ecosystem Services policies. Next, we use previously published data to estimate the potential economic benefits of implementing the Portuguese Prescribed Burning Program.

\subsection{Order of Magnitude Analysis}

An order of magnitude analysis provides efficient integration of quantitative and qualitative knowledge in the expression and solution of engineering problems. The order of magnitude analysis is based on seven primitive relations among absolute magnitudes of quantities: "much less than" $(<<)$, "moderately less than" $(-<)$, "slightly less than" $(\sim$ $<)$, "equal to" (= =), "slightly greater than" (> ), "moderately greater than" $(>-)$, and "much greater than" $(>>)$ [16]. It provides an initial approximation of the problem, serving as a framework to model the situation under study. The structure of the order of magnitude analysis employed in this study is shown in Fig. 1. 


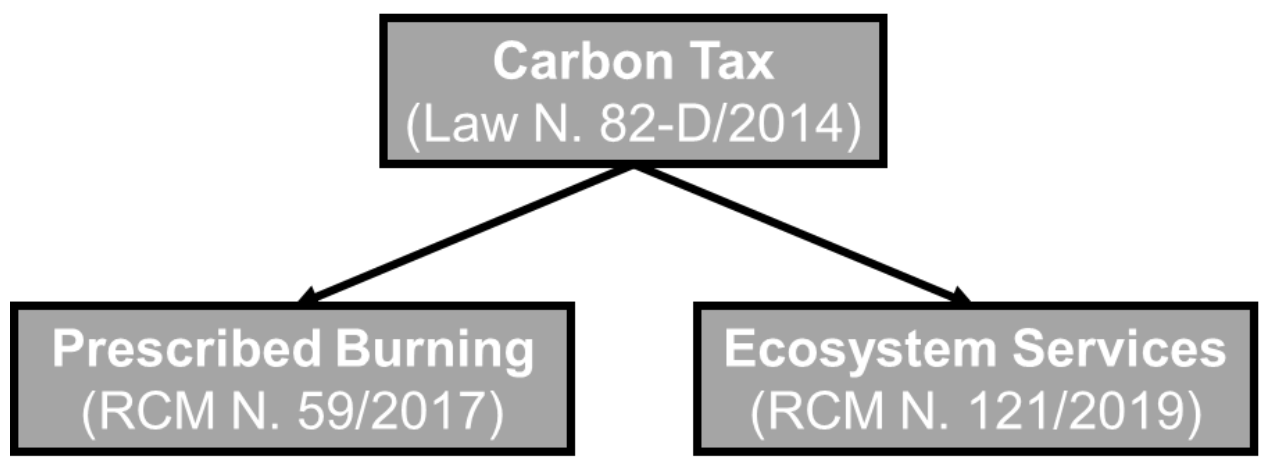

Fig. 1 - Structure of the order of magnitude analysis.

The Addition Tax revenue (Law N. 82-D/2014) was obtained for 2016 until 2018 through a report from the Technical Unit of Budget Support (UTAO, 2019). The cost of the Payment for Ecosystem Services policy was found in Notice N.13655/2019 (associated with RCM 121/2019), which accounts for the whole duration of the policy, from 2019 until 2038. Regarding the prescribed burning policy, its costs for 2017 and 2018 are projected in the National Prescribed Burning Plan (ICNF, 2017), an element of the National Prescribed Burning Program (RCM N. 59/2017).

\subsection{Prescribed Burning Benefits}

This part of the analysis is centred on the annual economic benefits that can be expected by adopting regular prescribed burning measures. We employ data from the study of Vilén and Fernandes [2], in which the authors used historical data to simulate the reduction in emissions for four prescribed burning treatment scenarios. Table 1 shows the scenarios simulated and expected emission reductions.

Table 1 - Scenario's description and estimated overall emission reductions in Portugal. Adapted from: Vilén and Fernandes (2011).

\begin{tabular}{|c|l|c|}
\hline Scenario & \multicolumn{1}{|c|}{ Description } & $\begin{array}{c}\text { Emission } \\
\text { Reduction }\end{array}$ \\
\hline I & $\begin{array}{l}\text { 2\% of the annually burned area treated by prescribed fire, assuming 1 ha } \\
\text { decrease in the area burned by wildfire for each treated ha }\end{array}$ & $1 \%$ \\
\hline II & $\begin{array}{l}\text { 2\% of the annually burned area treated by prescribed fire, assuming 3 ha } \\
\text { decrease in the area burned by wildfire for each treated ha }\end{array}$ & $5 \%$ \\
\hline III & $\begin{array}{l}\text { 20\% of the annually burned area treated by prescribed fire, assuming 1 ha } \\
\text { decrease in the area burned by wildfire for each treated ha }\end{array}$ & $13 \%$ \\
\hline IV & $\begin{array}{l}\text { 20\% of the annually burned area treated by prescribed fire, assuming 3 ha } \\
\text { decrease in the area burned by wildfire for each treated ha. }\end{array}$ & $52 \%$ \\
\hline
\end{tabular}

The annually burnt area estimated in this study is 109,327 ha (the average burnt area between 1980 and 2008), and the annual average $\mathrm{CO}_{2}$ emissions in wildfires are 4,408,808 Tons. To monetarily valuate these emissions savings, we multiply the carbon mass that was saved per treated hectare by the Addition Tax on Carbon Emissions values from 2016, when it started, until 2020.

According to Law N. 82-D/2014, the value of the tax for each year (n) is calculated in the previous year (n-1) as the arithmetic mean of the price resulting from auctions of greenhouse gas emission allowances, carried out within the framework of the European Union Emissions Trading System (EU ETS), between July $1^{\text {st }}$ of year n-2 and June $30^{\text {th }}$ of year n-1. Table 2 shows the evolution of the tax values. 
Table 2 - Variation of the Addition Tax on Carbon Emissions.

\begin{tabular}{|c|c|l|}
\hline Year & $\begin{array}{c}\text { Addition Tax on Carbon Emissions } \\
\left(€ / \mathrm{T} \text { of } \mathrm{CO}_{2}\right)\end{array}$ & \multicolumn{1}{|c|}{ Source } \\
\hline 2016 & 6.67 & Ordinance N. 420-B/2015 \\
\hline 2017 & 6.85 & Ordinance N. 10/2017 \\
\hline 2018 & 6.85 & Ordinance N. 384/2017 \\
\hline 2019 & 12.74 & Ordinance N. 6-A/2019 \\
\hline 2020 & 23.619 & Ordinance N. 22/2020 \\
\hline
\end{tabular}

The value of the Tax has been increasing through the years, which is largely due to the context following The Paris Climate Conference (COP21), that led the prices of carbon permits to rise to all-time highs after EU leaders reached a deal on more ambitious emissions cuts for this decade [17].

The data from these two sources are then used to compare the savings per hectare with the prescribed burning costs presented in the Portuguese National Prescribed Burning Plan (RCM N. 59/2017).

\section{Results and Discussion}

As is acknowledged by the European Commission, the biodiversity crisis and the climate crisis are intrinsically connected. Climate change accelerates the degradation of the natural world through more extreme climatic events, such as wildfires, while the loss and unsustainable use of nature are drivers of climate change [18]. Under these harsher climate conditions, it is likely that current fire suppression cannot control all wildfires, and its ability to do so might be compromised [3]. This justifies the need to proactively invest in wildfire prevention through prescribed burning and investing in biodiversity conservation. Next, the results of the order of magnitude analysis and economic benefits of the National Prescribed Burning Program are presented.

\subsection{Magnitude of Revenues and Investments}

The revenue from the Addition Tax and the investments needed for RCM N. 59/2017 and RCM N. 121/2019 are presented in Fig. 2, illustrating the order of magnitude analysis performed.

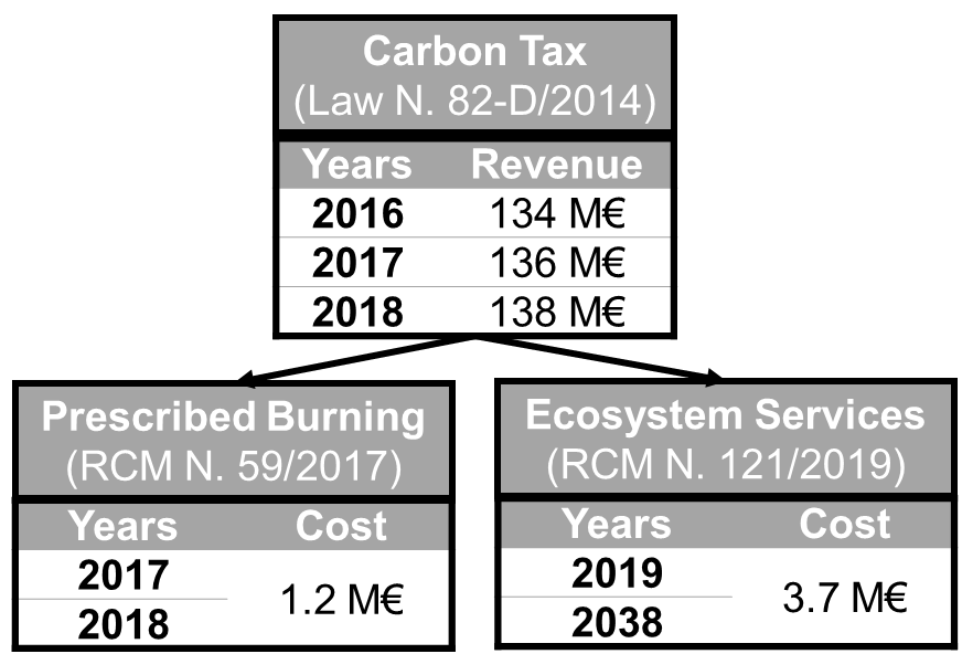

Fig. 2 - Order of magnitude analysis. The revenue from the Addition Tax in contrast with the costs of RCM N. 59/2017 and RCM N. 121/2019. 
From the information collected for this order of magnitude analysis, despite the distinguished timeframes analysed, it is evident that the revenue from the Addition Tax is "much greater than" the costs of the Payment for Ecosystem Services and Prescribed Burning policy. The revenue from the tax collected in 2016 alone is more than 25 times higher than the investments needed for the entire duration of the two policies.

By law, the revenue of the Addition Tax is directed to the Portuguese Environmental Fund. This Fund has the objective of supporting environmental policies aligned with the Sustainable Development Objectives, such as carbon sequestration, that can benefit from the implementation of RCM N. 59/2017 and RCM N. 121/2019 actions. Often ecosystem servicesbased solutions that can help in SDGs implementation are overlooked or underexploited [9].

Despite the viability of using a share of the revenue from the Addition Tax to fund these two policies, there are three main criticisms of financing natural climate solutions through carbon taxes, as pointed by Barbier et al. [13]. First, they can cause the shift of forest degradation to other areas. Second, they may decrease the incentive to reduce emissions via renewable energy. Third, the tax revenue should be used for different purposes. However, the authors believe that all these concerns can be addressed. A national tax scheme can reduce the probability of degradation shifts within each country. Renewableenergy production and natural climate solutions are both crucial. Lastly, despite the many worthy uses of tax revenue, the severity of climate change and biodiversity loss makes tackling both at once a priority.

This is also true in Portugal's case. First, the tax revenues would be employed in guarding the forest and the population against extreme fire events, according to the areas' vulnerability. Second, as the results indicated, the tax revenue far exceeds what is needed to invest in prescribed burning and biodiversity initiatives, leaving enough financial resources to be invested in renewable energies and more climate-focused actions. Lastly, climate actions and biodiversity are top concerns in the European and Portuguese environmental agenda, and therefore both should have a priority in using these funds.

\subsection{Prescribed Burning Program Benefits}

Sustainable forest management can help curb climate change by lowering greenhouse gas emissions and improving greenhouse gas absorption, acting as a carbon sink, storing carbon-containing chemicals for indefinite periods [7]. In this sense, prescribed burning measures can have a beneficial effect, as they help preserve vegetation cover, i.e., carbon storage. The technique has been shown to reduce overall carbon emissions in a range from $1 \%$ up to 52\%, depending on each scenario's level of intervention [2]. Table 3 shows the economic benefits associated with the emissions reductions linked to prescribed burning initiatives.

Table 3 - Monetary carbon savings associated with the prescribed burning scenarios of Vilén and Fernandes [2], and evolution of the Addition Tax value.

\begin{tabular}{|c|c|c|c|c|c|}
\hline \multirow{2}{*}{$\begin{array}{l}\text { Prescribed } \\
\text { Burning } \\
\text { scenarios }\end{array}$} & $\mathrm{CO}_{2} \operatorname{tax}-2016$ & $\mathrm{CO}_{2} \operatorname{tax}-2017$ & $\mathrm{CO}_{2}$ tax - 2018 & $\mathrm{CO}_{2} \operatorname{tax}-2019$ & $\mathrm{CO}_{2}$ tax -2020 \\
\hline & \multicolumn{5}{|c|}{$€ /$ treated ha } \\
\hline Scenario I & 134 & 138 & 138 & 257 & 476 \\
\hline Scenario II & 672 & 691 & 691 & 1284 & 2381 \\
\hline Scenario III & 175 & 180 & 180 & 334 & 619 \\
\hline Scenario IV & 699 & 718 & 718 & 1336 & 2476 \\
\hline
\end{tabular}

Considering the Addition Tax values from 2016 until 2020, monetary emission savings vary from 134 up to 2476 euros/treated hectare. When contrasting these monetary savings with the treatment cost of 120 euros/treated hectare presented in the Portuguese National Prescribed Burning Plan, it becomes evident that, in addition to being attractive from an environmental perspective, this policy is also economically interesting.

Furthermore, reduced fire suppression and debris removal costs are also expected, besides less significant economic losses than anticipated with large fires [19]. In this context, cost-effective ways to help forests become more resilient to fires, such as prescribed burning, can play a key role in guarding lives and ecosystems, not only in Portugal but worldwide. 


\section{Conclusion}

Climate change and its consequences, such as wildfires and biodiversity loss, are major challenges of the century and need to be tackled as efficiently as possible. In fact, there is evidence of the benefits of addressing climate change and forest policies jointly through new governance arrangements [14].

This was a two-part study. First, the order of magnitude study aimed to provide an initial assessment of the economic viability of using the revenue from the Addition Tax on Carbon Emissions for funding wildfire prevention and biodiversity policies, both in alignment with climate change prevention and mitigation. The results indicate that the tax revenue is "much greater than" what is needed for investing in wildfire prevention and biodiversity conservation through the established policies. From an environmental perspective, there is clear evidence of the potential benefits of all these policies and that they can work synergistically since they all have positive impacts in mitigating climate change.

Finally, having analysed RCM N. 59/2017 through an ecosystem services valuation approach, we have provided evidence that indicates that the benefit per hectare provided by prescribed burning exceeds its cost, and by far in some cases. Analyses such as the ones presented in this study are valuable in illustrating the possibility of synergies among different environmental policies and the usefulness of the valuation of ecosystems services approach in this context. The analysis framework employed in this study might be helpful for other countries, especially in the Mediterranean region.

\section{Acknowledgements}

This work was financially supported by Operation NORTE-08-5369-FSE-000045 co-funded by the European Social Fund (FSE) through NORTE 2020 - Programa Operacional Regional do NORTE. This work was also financed by National Funds through the Portuguese funding agency, FCT - Fundação para a Ciência e a Tecnologia, within project UIDB/50014/2020.

\section{References}

[1] S. E. Shmelev and S. U. Speck, "Green fiscal reform in Sweden: Econometric assessment of the carbon and energy taxation scheme," Renew. Sustain. Energy Rev., vol. 90, no. March, pp. 969-981, 2018.

[2] T. Vilén and P. M. Fernandes, "Forest fires in Mediterranean countries: CO 2 emissions and mitigation possibilities through prescribed burning," Environ. Manage., vol. 48, no. 3, pp. 558-567, 2011.

[3] A. Duane, N. Aquilué, Q. Canelles, A. Morán-Ordoñez, M. De Cáceres, and L. Brotons, "Adapting prescribed burns to future climate change in Mediterranean landscapes," Sci. Total Environ., vol. 677, pp. 68-83, 2019.

[4] A. Carvalho, L. Schmidt, F. D. Santos, and A. Delicado, "Climate change research and policy in Portugal," Wiley Interdiscip. Rev. Clim. Chang., vol. 5, no. 2, pp. 199-217, 2014.

[5] C. Narayan, P. M. Fernandes, J. van Brusselen, and A. Schuck, "Potential for CO2 emissions mitigation in Europe through prescribed burning in the context of the Kyoto Protocol," For. Ecol. Manage., vol. 251, no. 3, pp. 164-173, 2007.

[6] M. Guo, J. Li, L. Wen, and S. Huang, "Estimation of CO2 emissions from Wildfires using OCO-2 data," Atmosphere (Basel)., vol. 10, no. 10, pp. 1-16, 2019.

[7] J. Liu and F. Wu, "Forest carbon sequestration subsidy and carbon tax as part of China's forestry policies," Forests, vol. 8, no. 3, pp. 1-15, 2017.

[8] I. Kelman, "Linking disaster risk reduction, climate change, and the sustainable development goals," Disaster Prev. Manag., vol. 26, no. 3, pp. 254-258, 2017.

[9] S. Yang, W. Zhao, Y. Liu, F. Cherubini, B. Fu, and P. Pereira, "Prioritizing sustainable development goals and linking them to ecosystem services: A global expert's knowledge evaluation," Geogr. Sustain., vol. 1, no. 4, pp. 321-330, 2020.

[10] M. Nilsson, D. Griggs, and M. Visbeck, "Policy: Map the interactions between Sustainable Development Goals," Nature, vol. 534, no. 7607, pp. 320-322, 2016.

[11] R. D. Cairns and P. Lasserre, "Reinforcing economic incentives for carbon credits for forests," For. Policy Econ., vol. 6, no. 3-4, pp. 321-328, 2004. 
[12] T. Wu, Y. S. Kim, and M. D. Hurteau, "Investing in Natural Capital: Using Economic Incentives to Overcome Barriers to Forest Restoration," Restor. Ecol., vol. 19, no. 4, pp. 441-445, 2011.

[13] E. B. Barbier, R. Lozano, C. M. Rodríguez, and S. Troëng, "Adopt a carbon tax to protect tropical forests," Nature, vol. 578, no. 7794, pp. 213-216, 2020.

[14] M. Doelle, C. Henschel, J. Smith, C. Tollefson, and A. Wellstead, "New governance arrangements at the intersection of climate change and forest policy: Institutional, political and regulatory dimensions," Public Adm., vol. 90, no. 1, pp. 37-55, 2012.

[15] T. M. Oliveira, N. Guiomar, F. O. Baptista, J. M. C. Pereira, and J. Claro, "Is Portugal's forest transition going up in smoke?," Land use policy, vol. 66, pp. 214-226, 2017.

[16] M. L. Mavrovouniotis and G. Stephanopoulos, "Order-of-magnitude reasoning with O [ M ]," vol. 4, no. 3, pp. 106$114,1989$.

[17] N. Chestney, "EU carbon price rises to all-time high after EU climate deal | Reuters," Reuters, 2020.

[18] European Commision, "EU Biodiversity Strategy for 2030: Bringing nature back into our lives," 2020.

[19] M. E. Hunter and M. D. Robles, "Tamm review: The effects of prescribed fire on wildfire regimes and impacts: A framework for comparison,” For. Ecol. Manage., vol. 475, no. April, 2020. 